\title{
Identification and Characterization of Chickpea Genotypes for Early Flowering and High Seed Germination through Molecular Markers
}

\section{Garima Yadav}

ICAR - Indian Institute of Seed Science

Deepanshu Jayaswal

ICAR - Indian Institute of Seed Science

Kuldip Jayaswall

ICAR - Indian Institute of Seed Science

\section{Abhishek Bhandawat}

National Agri-Food Biotechnology Institute: National Agri-Food Biotechnology Institute

ArvindNath Singh

ICAR - Indian Institute of Seed Science

Jyotsana Tilgam

National Bureau of Agriculturally Important Microorganisms

Abhishek Kumar Rai

ICAR - Indian Institute of Seed Science

Rachna Chaturvedi

Amity University

Ashutosh Kumar

ICAR - Indian Institute of Seed Science

\section{Sanjay Kumar}

ICAR - Indian Institute of Seed Science

S P Kumar ( $\Delta$ jeevanicar@gmail.com )

Directorate of Floricultural Research https://orcid.org/0000-0003-4050-4142

\section{Research Article}

Keywords: Chickpea, Cross-species transferability,Genetic diversity, ISSR markers

Posted Date: November 10th, 2021

DOI: https://doi.org/10.21203/rs.3.rs-1033758/v1 
License: (c) (i) This work is licensed under a Creative Commons Attribution 4.0 International License. Read Full License 


\section{Abstract}

Chickpea is the fourth most important legume crop contributing 3.1\% to the total legume production and rich source of proteins, minerals and vitamins. Genetic diversity of wild and elite cultivar is quintessential for variety improvement. Determination of genetic diversity is more reliable and accurate, therefore, commonly used. In the present study, we analyzed the genetic diversity, population structure, crossspecies transferability and allelic richness in 50 chickpea collection using 23 ISSR markers. The observed parameters such as allele number varied from 3 to 16,and polymorphic information content (PIC) varied from 0.15 to 0.4988 , respectively. Further, range of allele size varied from 150 to $1600 \mathrm{bp}$, which shows the significance of ISSR markers for chickpea germplasm characterization. On the basis of ISSR marker genotypic data, dendrogram was constructed which divides these 50 chickpea in group I and II showing the reliability of ISSR markers. Among 50 chickpea, the accession P 74-1 is in group I and rest are in group II. Further we made mini-core collection of 15 diverse chickpea and sub-grouped them. Dendrogram, PCA, Dissimilarity matrix and Bayesian model based genetic clustering of 50 chickpea germplasms revealed that P 74-1 and P 1883are very diverse chickpea accession. Further selected 15 diverse chickpea screened for early flowering and high seed germination. Among 15 diversechickpea germplasms P 1857-1 and P 3971 has early flowering and high seed germination compared to P 1883 and other germplasm. Characterization of these diverse chickpea for early flowering and high seed germinationwould help in reducing crop duration and enhancing seed qualities. Utilization of these ISSRs markers in diversity analysis and population structure characterization of 50 chickpea germplasm suggests their wider efficacy for molecular breeding ofearly flowering and high seed germination.

\section{Introduction}

Among various leguminous crops, chickpea is the fourth most important legume contributing $3.1 \%$ to the total legume production (http://faostat.fao.org). Chickpea is the rich source of proteins, minerals and vitamins which makes them suitable for both food and feed. There are total 43 species that have been reported under the genus Cicer among which only one species i.e., Cicer arietinum L. is under cultivation that have economic importance (Sethyet. al., 2006a). The genome sequence data revealed the genome size ( $750 \mathrm{Mbp}$ ) with 8 basic set of chromosome (Sethy et. al., 2006b). For any crop to be improved, the knowledge of genetic diversity of wild and elite cultivar is very important. Before 1980s when molecular markers were not known, genetic diversity and relationship were analyzed by biochemical markers. Further, the discovery of molecular markers has made the genetic diversity analysis easy.

Among various available marker systems, molecular markers are more reliable and accurate, therefore are very commonly used for genetic diversity analysis, phylogenetic studies and cultivar identification. Due to continuous selection breeding for crop improvement, genetic polymorphisms in the cultivated Cicer arietinum $\mathrm{L}$. are very low, hence marker assisted selection (MAS) and marker assisted breeding (MAB) could play very potential role in the development of new varieties. Since past many years, genetic diversity analysis with different molecular markers in various crops has been done efficiently (Ahmad, 1999; Queen et. al., 2004; Schulman, 2007; Gill-Langaricaet. al., 2011; Noormohammadiet. al., 2013; 
Bonmanet. al., 2015; Moggaet. al., 2018; Elshafeiet. al., 2019; Delfiniet. al., 2021). Due to several advantages of Inter Simple Sequence Repeat (ISSR) markers over other markers such as PCR based, no requirement of sequence information, distribution across the whole genome, require small quantity of template DNA and cost effective, ISSR markers are extensively used for genetic diversity analysis. The genotypic data of ISSR marker, pedigree analysis and various phenotypic data can assist in the selection of germplasm for further crop improvement through molecular breeding programs (Raoet. al., 2007).

In this study we analyzed the genetic diversity, structure, cross-species transferability and allelic richness in 50 chickpea collection using 23 ISSR markers. The observed parameters such as allele number varied from 3 to 16,and PIC varied from 0.15 to 0.4988 , respectively. Further, range of allele size varied from 150 to 1600 bp which shows the significance of ISSR markers for chickpea germplasmscharacterization. On the basis of ISSR marker genotypic data dendrogram were constructed which divides these 50 chickpea in group I and II showing the reliability of ISSR markers. Among 50 chickpea, the accession P 74-1 is in group I and rest are in group II. Further we made mini-core collection of 15 diverse chickpea and sub grouped them. Dendrogram, PCA, Dissimilarity matrix and Bayesian model based genetic clustering of 50 chickpea germplasms revealed that P 74-1,P 1883, P 1260 very diverse chickpea accession.Additionally we have screened 50 chickpea germplasms for early flowering and high seed germination. Among 15 diverse chickpea germplasms P 1857-1 and P 3971 have early flowering and high seed germination compared to $P 1883$ and other germplasm. Characterization of these diverse chickpea would help in maintenance breeding, conservation and in future could be used to develop climate resilient elite cultivar of chickpea. The study of genetic diversity and population structure of 50 chickpea and development of 15 chickpea core collection will serve as important knowledge resources for future studies like GWAS, and mapping and introgression of early flowering and high seed germination in elite cultivar.

\section{Material And Methods}

\section{Plant Material}

Total fifty individuals of wild chickpea germplasm (Supplementary Table 1)were grown in the field of ICAR-IISS, Mau, India. Genomic DNA from freshly procured leaves of chickpeawas isolated by CTAB method with minor modification (Murray and Thompson, 1980). The wild chickpea germplasm having varying concentrations of secondary metabolite content and to overcome the inhibitory effect of secondary metabolite content during DNA extraction, the concentration of polyvinyl pyrrolidone $\mathrm{K}-30$ and $\beta$-mercaptoethanol were standardized. Further, the quality of extracted DNA was examined over $0.8 \%$ agarose gel using lambda uncut marker (Fermentas, Lithuania) and quantified by NanoDrop 2000 (Thermo Scientific, USA).

\section{Amplification validation and polymorphic potential evaluation}


Fifty chickpea germplasm were genotyped by 23 inter simple sequence repeat (ISSR) markers (Supplementary Table-1) and DNA fingerprint was developed (Table-1). For all the, PCR amplification efficiency with 23 ISSR markers were analyzed in $25 \mu \mathrm{L}$ reaction volume with $20 \mathrm{ng}$ of DNA template. The PCR program initiated by pre-denaturation step at $94^{\circ} \mathrm{C}$ for $5 \mathrm{~min}$, subsequent 35 cycles of denaturation at $94^{\circ} \mathrm{C}$ for $1 \mathrm{~min}$, annealing at optimum temperature $50^{\circ} \mathrm{C}$ for $1 \mathrm{~min}$, primary extension at $72^{\circ} \mathrm{C}$ for $2 \mathrm{~min}$ and the final extension was done at $72^{\circ} \mathrm{C}$ for $10 \mathrm{~min}$ in Thermo Cycler (Eppendorf). The amplified PCR products were separated on $1.5 \%$ agarose gel, and amplicon size were estimated based on $100 \mathrm{bp}$ DNA ladder (Genedirex) as a reference.

\section{Molecular data analysis}

The amplification profiles with ISSR markers were scored based on their presence (1) or absence (0) across all individuals (SupplementaryTable-2). The amplified product were categorized as monomorphic, polymorphic and null alleles on the basis of same, different and absence of amplified PCR product across all the individuals. Cross-transferability of the ISSR markers and amplicon size were recorded for all the chickpea germplasms to construct UPGMA dendrogram and Principle Component Analysis (PCA) based on Jaccard's coefficient using DARwin6 (ver.) software (Perrier and Jacquemoud-Collet 2006). The polymorphic information content (PIC) values were calculated for each marker using online PIC calculator (https://www.liverpool.ac.uk/ kempsj/pic.html) (Table-1). Genetic structures of fifty individuals of chickpeawere inferred using Bayesian algorithm-based STRUCTURE software (ver. 2.3.3) (Pritchard et al., 2000; Falush et al., 2007). Further dissimilarity matrix (SupplementaryTable-3) was measured using DARwin6 software (Perrier and Jacquemoud-Collet 2006).

\section{Phenotyping of minicore collection for early flowering and high seed germination}

$50 \%$ flowering data were taken day after showing between 45 days to 65 days to select early, moderate and late flowering germplasms. For germination test, paper towel was moistened with distilled water and kept at $25^{\circ} \mathrm{C}$ and constant light. Further the days of $50 \%$ emergence under field condition was measured.

\section{Result And Discussion}

Genome of plants has several repeated DNA sequence such as Inter Simple Sequence Repeats (ISSR) and Simple Sequence Repeats (SSRs). In the past, when these sequence repeats were considered as'junk' DNA which have been used for plant genetic diversity analysis but with the time when sequencing technologies evolved, now it is well known that these sequence repeats are the major part of plant genome regulate gene expression and packing of genomes. ISSRs are usually repetitive DNA sequences mostly 1-6 bases (Littet al., 1989) which are PCR based, do not require prior sequence information, distributed throughout the genome, polymorphic and are cross transferable (Welsh et al., 1990, Wang et 
al., 1994). Chickpea (CicerarietinumL.) belongs to the family leguminosae, is the fourth most important pulse crop of the world and India is among the largest producer country (FAO, 2010).Chickpea seeds are nutrient rich due to the presence of balanced protein, carbohydrates, vitamins and minerals with the low levels of anti-nutritional factors (Wang et. al., 2010; Santiago et. al., 2010). Various biotic and abiotic stresses reduce the chickpea production across the globe, therefore, bringing of desirable traits in elite cultivar of chickpea from crossable donor cultivar is need of the hour (Singh et. al., 2008). In this scenario, ISSRs markers could play potential role for comparative genomics study, traits identification, genetic purity, association studies and introgression of desirable traits in chickpea through marker-assisted breeding (Gautamet. al., 2016; Jayaswallet. al., 2019b; Jayaswallet. al., 2019a).

\section{Scoring and data analysis}

Twenty five ISSR markers were selected for identification of polymorphism, cross-species transferability, genetic diversity and population structure analysis in 50 chickpea germplasms. Among twenty five only 23 ISSR markers were amplified at least in one of the individuals of chickpea. The amplification failure in some chickpeas could be due to not binding of primers in the genome. In present study, polymorphism was found to be higher than SSRs due to random binding of ISSR primers to the genome of diverse chickpea germplasms. The observed parameters like allele number varied from 3-16, allele size varied from $150-1600$ bases and polymorphic information content (PIC) value ranges from 0.15 to 0.4988 (Table 1).

Table 1

List of primers and their amplification characteristics 


\begin{tabular}{|c|c|c|c|c|c|c|}
\hline $\begin{array}{l}\text { S. } \\
\text { No. }\end{array}$ & $\begin{array}{l}\text { Locus } \\
\text { name }\end{array}$ & Primer sequence & $\begin{array}{l}\text { Annealing } \\
\text { temperature } \\
(\mathrm{Ta})^{\circ} \mathrm{C}\end{array}$ & $\begin{array}{l}\text { No. of } \\
\text { alleles }\end{array}$ & PIC & $\begin{array}{l}\text { Approximate } \\
\text { size range } \\
\text { (bp) }\end{array}$ \\
\hline 1 & UBC 807 & AGAGAGAGAGAGAGAGT & 50 & 13 & 0.48 & $150-650$ \\
\hline 2 & UBC 808 & AGAGAGAGAGAGAGAGG & 50 & 7 & 0.4669 & $320-1400$ \\
\hline 3 & UBC 809 & AGAGAGAGAGAGAGAGG & 50 & 5 & 0.2522 & $300-1200$ \\
\hline 4 & UBC 810 & GAGAGAGAGAGAGAGAT & 50 & 8 & 0.2952 & $300-1300$ \\
\hline 5 & UBC 811 & GAGAGAGAGAGAGAGAC & 50 & 11 & 0.4721 & $250-1300$ \\
\hline 6 & UBC 812 & GAGAGAGAGAGAGAGAA & 50 & 12 & 0.4916 & $250-1450$ \\
\hline 7 & UBC813 & стстстстстстстстт & 50 & 3 & 0.3432 & $400-1200$ \\
\hline 8 & UBC 815 & стстстстстстстстя & 50 & 6 & 0.4997 & $350-1200$ \\
\hline 9 & UBC 817 & CACACACACACACACAA & 50 & 3 & 0.457 & $1000-1250$ \\
\hline 10 & UBC 818 & CACACACACACACACAG & 50 & 3 & 0.1583 & $400-1200$ \\
\hline 11 & UBC 819 & GTGTGTGTGTGTGTGTA & 50 & 8 & 0.499 & $300-1200$ \\
\hline 12 & UBC 820 & GTGTGTGTGTGTGTGTT & 50 & 7 & 0.4953 & $400-1200$ \\
\hline 13 & UBC 822 & ТСТСТСТСТСТСТСТСА & 50 & 6 & 0.4002 & $300-1200$ \\
\hline 14 & UBC 824 & ТСТстстстстСТСТСG & 50 & 16 & 0.4947 & $250-1200$ \\
\hline 15 & UBC 825 & ACACACACACACACACT & 50 & 6 & 0.3394 & $700-1250$ \\
\hline 16 & UBC 826 & ACACACACACACACACC & 50 & 5 & 0.463 & $750-1500$ \\
\hline 17 & UBC 827 & ACACACACACACACACG & 50 & 6 & 0.4772 & $600-1100$ \\
\hline 18 & UBC 834 & AGAGAGAGAGAGAGAGYT & 50 & 9 & 0.4975 & $250-1300$ \\
\hline 19 & UBC 835 & AGAGAGAGAGAGAGAGYC & 50 & 9 & 0.3761 & $250-1250$ \\
\hline 20 & UBC 840 & GAGAGAGAGAGAGAGAYT & 50 & 8 & 0.4955 & $300-1600$ \\
\hline 21 & UBC 841 & GAGAGAGAGAGAGAGAYC & 50 & 6 & 0.3506 & $300-800$ \\
\hline 22 & UBC 842 & GAGAGAGAGAGAGAGAYG & 50 & 9 & 0.4988 & $200-1100$ \\
\hline 23 & UBC 856 & ACACACACACACACACYA & 50 & 3 & 0.0768 & $500-750$ \\
\hline
\end{tabular}




\section{Understanding of taxon and genetic relationship among $\mathbf{5 0}$ chickpea germplasms}

In plant molecular breeding, the genetic variability is a primary requirement and further, population structure analysis in the selection of elite diverse germplasms (Chakrabortyet. al., 2016). The rationale of the genetic structure analysis is to understand the population homogeneousity and genetic variability. Population structure is required for mapping of agronomically important genes and dissection of important traits (Wei et al., 2006). Twenty three ISSRs markers were selected for screening of cross transferability and polymorphism studies in 50 chickpea germplasm. Based on the data from 23 ISSR markers (2 ISSRs were not amplified) dendrogram were constructed that divides 50 chickpea germplasms into two group (group I, \& II). In group I, germplasm P 74-1 is highly diverse and remaining 49 chick pea fall in group II which have been further divided in different subgroups. Based on UPGMA dendrogram (Fig.1) we selected diverse 15 chickpea core collection (Table 2).Germplasms P 741, P 1883, and P 1260 belongs to I, IIB, IIBb, subgroup respectively(Fig.1). Further in Polymorphic Component analysis (PCA), they fall in cluster I (Fig.2). Additionally in structure analysis they belongs to cluster A (Fig.3). Further it was observed that dissimilarity of P 74-1, P 1883, P 1260 to germplasm P 4051 is $78 \%, 55 \%, 54 \%$ respectively (Table 2 and Supplementary table 3 ). Dendrogram, PCA , Dissimilarity matrix and Bayesian model based genetic clustering of 50 chickpea germplasms reveal that $P$ 74-1, $P$ 1883, and P 1260 are very diverse than chickpea germplasms $P 4051$.

Table 2

Panel of core collection of 15 chickpea germplasms 
Further, P 556, P 625, P 886, P 55, P 341 belongs to IIBa2, IBa1v, IBa1v, IBa1v, and IBa1v group respectively. Germplasm P 556, P 625, P 886, P 55, and P 341 falls in cluster II(Fig.1). P 556, P 625, P 886, P 55, P 341 germplasm also belong to cluster A of Bayesian model based genetic clustering of 50 chickpea germplasms(Fig.2). AdditionallyP 556, P 625, P 886, P 55, P 341 has dissimilarity 46\%, 40\%, 40\%, 40\%, and 40\%, respectively(Table 2 and Supplementary table 3)from chickpea germplasm P 4051. P 1107 and $P 1137$ which belongs to cluster IIBa1w of UPGMA dendrogram(Fig.1).Additionally P 1107 and P 1137 belong to group I of two dimensional distributions of 50 chickpea

germplasms(Fig.2).Germplasms P 1107 and P 1137 belong to cluster $A$ of Bayesian model based genetic clustering of 50 chickpea germplasms(Fig.3). P 1107 and P 1137 both have dissimilarity 39\% from chickpea germplasm P 4051(Table 2 and Supplementary table 3).P 1857 falls in group IIBa1x of UPGMA dendrogram (Fig.1).and belongs to IV cluster of two dimensional distributions of 50 chickpea germplasms (Fig.2). It belongs to cluster B of Bayesian model based genetic clustering of 50 chickpea germplasms(Fig.3).Its dissimilarity is 35\% from chickpea germplasm P 4051(Table 2 and Supplementary table 3). Germplasm P 1217, P 1548, P 1781, P 3971 belongs to group IIBa1w of UPGMA dendrogram(Fig.1).Germplasms P 1217, P 1548, P 1781, and P 3971 belongs to cluster III of two dimensional distributions of 50 chickpea germplasms(Fig.2).P 1217, P 1548, P 1781, and P 3971 germplasms fall in cluster $\mathrm{B}$ of Bayesian model based genetic clustering of 50 chickpea germplasms(Fig.3).All P 1217, P 1548, P 1781, P 3971 has dissimilarity 33\%, 33\%, 28\% and 16\% respectively from chickpea germplasm P 4051(Table 2 and Supplementary table 3). So dendrogram of 50 chickpea germplasms based on 23 inter simple sequence repeats (ISSR) markers (Fig.1), ISSR marker based principle component analysis (PCA) showing two dimensional distributions of 50 chickpea germplasms (Fig.2), Bayesian model based genetic clustering of 50 chickpea germplasms (Fig.3), triangle plot of 50 chickpea germplasms (Fig.4) reveals that all 15 core collection of chickpea are very diverse and could be used to molecular breeding by utilizing these ISSR markers.

\section{Identification of early flowering and high seed germination lines}

Present study was carried out on chickpea genotype to identify early flowering and high seed germination lines.In current study, 50 individuals were DNA fingerprinted and 15 diverse chickpea minicore collection developed. All selected 15 chickpea lines screened for early flowering and high seed germination.Among these 15 individuals, four were identified under early flowering and six were high seed germination lines.Among 15 diverse chickpea P 1857-1 and P 3971 have both early flowering and high seed germination trait compared to P 1883 and other germplasms. Among these 15 lines,P 1857-1 and P 3971 both showed strong correlation among themselves for early flowering and high seed germination compared to other 13 individual(fig-5b,6b)The chickpea correlation heatmap matrix(fig-5a,6a) of the early flowering and high seed germination linesfurther confirmed the DNAgenotype and heatmap data of the obtained for early flowering and high seed germination lines for the identification of early flowering and high seed germinationlines. 
Therefore information about relatedness of various chickpea within and between group I, and II provides radiant prospect to bring various agronomically desirable traits such as of early flowering and high seed germinationfrom donor chick pea to elite cultivated chickpea through marker assisted selection and breeding. Characterization of these diverse chickpeas would help in maintenance breeding, conservation and could be used in future to develop climate resilient chickpea to assist in food security.

\section{Conclusion}

ISSRs in genome influence activity and function of other nuclear and organelle coding gene due to their repeat length. Unfortunately, ISSR marker resources for chickpea have not been well harnessed for genotypic improvement of chickpea. Therefore, a set of 23 ISSRs have been used to expedite molecular breeding of chickpea. High cross transferability and polymorphism of these ISSR markers further reveal their novelty. Utilization of these novel ISSRs markers in diversity analysis and population structure characterization of 50 chickpea germplasm suggests their wider efficacy in superior scale for molecular breeding studies in chickpea. The study of genetic diversity and population structure of 50 chickpea and development of 15 chickpea core collection will serve as important knowledge resources for future studies like GWAS, and mapping.Identified P 1857-1 and P 3971 early flowering and high seed germination would act as a breeding material for introgression of early flowering and high seed germination trait into elite cultivar.

\section{Declarations}

\section{Author Contribution statement}

DJ, and KJ Conceived and designed the study. GY, AK and JT performed the experiment. ANS, AK, RC, AK, SK and JK helped in the preparation of draft manuscript. SK and JK performed the critical revision of the article. SPJK edited the final draft. All authors approved the final version of the article.

\section{Ethical approval}

This article does not contain any studies with animals performed by any of the authors.

\section{Compliance with Ethical Standards}

No funding was received for the current research.

\section{Acknowledgements}

Financial assistance for research by Indian Council of Agricultural Research-Indian Institute of Seed Sciences, Mau is gratefully acknowledged. Further ICRISAT,Hyderabad is gratefully acknowledged for 
providing chickpea germplasms.

\section{Conflict of interest}

The authors declare that they have no conflict of interest.

\section{References}

1. Ahmad F (1999) Random amplified polymorphic DNA (RAPD) analysis reveals genetic relationships among the annual Cicer species. Theor Appl Genet 98(3-4):657-663

2. Araki N, Masuzaki SI, Tsukazaki H, Yaguchi S, Wako T, Tashiro Y, Yamuchi N, Shigyo M (2010) Development of microsatellite markers in cultivated and wild species of section Cepa and Phyllodolon in Allium. Euphytica 173(3):321-328

3. Bonman JM, Babiker EM, Cuesta-Marcos A, Esvelt-Klos K, Brown-Guedira G, Chao S, Gordon TC (2015) Genetic diversity among wheat accessions from the USDA National Small Grains Collection. Crop Sci 55(3):1243-1253

4. Chakraborty D, Wang T, Andre K, Konnert M, Lexer MJ, Matulla C, Schueler S (2016) Adapting Douglas-fir forestry in Central Europe: evaluation, application, and uncertainty analysis of a genetically based model. Eur J For Res 135(5):919-936

5. Delfini J, Moda-Cirino V, dos Santos Neto J, Ruas PM, Sant'Ana GC, Gepts P, Gonçalves LSA (2021) Population structure, genetic diversity and genomic selection signatures among a Brazilian common bean germplasm. Sci Rep 11(1):1-12

6. Elshafei AA, Afiah SAEA, Al-Doss AA, Ibrahim El (2019) Morphological variability and genetic diversity of wheat genotypes grown on saline soil and identification of new promising molecular markers associated with salinity tolerance. J Plant Interact 14(1):564-571

7. Falush D, Stephens M, Pritchard JK (2007) Inference of population structure using multilocus genotype data: dominant markers and null alleles. Mol Ecol Notes 7(4):574-578

8. Falush D, Stephens M, Pritchard JK (2007) Inference of population structure using multilocus genotype data: dominant markers and null alleles. Mol Ecol Notes 7(4):574-578

9. FAO, Agriculture Data (2010)United Nations Food and Agriculture Organization

10. Gautam AK, Gupta N, Bhadkariya R, Srivastava N, Bhagyawant SS (2016) Genetic diversity analysis in chickpea employing ISSR markers. Agrotechnology 5(2):2168-9881

11. Gill-Langarica HR, Muruaga-Martínez JS, Vargas-Vázquez ML, Rosales-Serna R, Mayek-Pérez N (2011) Genetic diversity analysis of common beans based on molecular markers. Genetics and Molecular Biology 34(4):595-605

12. Jayaswall K, Bhandawat A, Sharma H, Yadav VK, Mahajan V, Singh M (2019) Characterization of Allium germplasms for conservation and sustainable management using SSR markers 
13. Jayaswall K, Sharma H, Bhandawat A, Sagar R, Yadav VK, Sharma V, Singh M (2019) Development of intron length polymorphic (ILP) markers in onion (Allium cepa L.), and their cross-species transferability in garlic (A. sativum L.) and wild relatives. Genet Resour Crop Evol 66(7):1379-1388

14. Kumar K, Bhattacharjee S, Vikuntapu PR, Sharma CL, Jayaswal D, Sharma R, Sundaram RM (2020) Climate change mitigation and adaptation through biotechnological interventions. In: Ch, Srinivasarao et al (eds) Climate change and indian agriculture: challenges and adaptation strategies. ICAR-National Academy of Agricultural Research Management, Hyderabad, Telangana, India, pp 122

15. Litt M, Luty JA (1989) A hypervariable microsatellite revealed by in vitro amplification of a dinucleotide repeat within the cardiac muscle actin gene. Am J Hum Genet 44(3):397

16. Mainkar PS, Manoj ML, Jayaswal D, Agarwal Y (2020) Identification and in-silico characterization of Serpin genes in legumes genomes. Indian J Agric Sci 90(9):1763-8

17. Meena RK, Kumar K, Dubey SK, Singh AK, Kumar A, Jayaswal D, Jain S (2021) Molecular Breeding Approaches for Improvement and Development of Water Saving Aerobic Rice.Molecular Breeding for Rice Abiotic Stress Tolerance and Nutritional Quality:382-397

18. Mogga M, Sibiya J, Shimelis H, Lamo J, Yao N (2018) Diversity analysis and genome-wide association studies of grain shape and eating quality traits in rice (Oryza sativa L.) using DArT markers. PLoS ONE 13(6):e0198012

19. Murray MG, Thompson WF (1980) Rapid isolation of high molecular weight plant DNA. Nucleic Acids Res 8(19):4321-4326

20. Noormohammadi Z, Sheidai M, Ghasemzadeh-Baraki S, Alishah O (2013) Genetic diversity analysis in Opal cotton hybrids based on SSR, ISSR, and RAPD markers. Genetics and molecular research: GMR 12(1):256-269

21. Perrier $X$, Jacquemoud-Collet JP (2006) DARwin software: Dissimilarity analysis and representation for windows. Website http://darwin.cirad. fr/darwin [accessed 1 March 2013]

22. Pritchard JK, Stephens M, Rosenberg NA, Donnelly $P$ (2000) Association mapping in structured populations. The American Journal of Human Genetics 67(1):170-181

23. Queen RA, Gribbon BM, James C, Jack P, Flavell AJ (2004) Retrotransposon-based molecular markers for linkage and genetic diversity analysis in wheat. Mol Genet Genomics 271(1):91-97

24. Rao LS, Rani PU, Deshmukh PS, Kumar PA, Panguluri SK (2007) RAPD and ISSR fingerprinting in cultivated chickpea (Cicerarietinum L.) and its wild progenitor CicerreticulatumLadizinsky. Genet Resour Crop Evol 54(6):1235-1244

25. Santiago RC, Moreira-Araújo RDR, e Silva MP, Arêas JAG (2001) The potential of extruded chickpea, corn and bovine lung for malnutrition programs. Innovative Food Science \& Emerging Technologies 2(3):203-209

26. Schulman AH (2007) Molecular markers to assess genetic diversity. Euphytica 158(3):313-321

27. Sethy NK, Choudhary S, Shokeen B, Bhatia S (2006) Identification of microsatellite markers from Cicerreticulatum: molecular variation and phylogenetic analysis. Theor Appl Genet 112(2):347-357 
28. Sethy NK, Shokeen B, Edwards KJ, Bhatia S (2006) Development of microsatellite markers and analysis of intraspecific genetic variability in chickpea (Cicer arietinum L.). Theor Appl Genet 112(8):1416-1428

29. Singh R, Sharma P, Varshney RK, Sharma SK, Singh NK (2008) Chickpea improvement: role of wild species and genetic markers. Biotechnol Genet Eng Rev 25(1):267-314

30. Wang N, Hatcher DW, Tyler RT, Toews R, Gawalko EJ (2010) Effect of cooking on the composition of beans (Phaseolus vulgaris L.) and chickpeas (Cicerarietinum L.). Food Res Int 43(2):589-594

31. Wang Z, Weber JL, Zhong G, Tanksley SD (1994) Survey of plant short tandem DNA repeats. Theor Appl Genet 88(1):1-6

32. Wei X, Jackson PA, McIntyre CL, Aitken KS, Croft B (2006) Associations between DNA markers and resistance to diseases in sugarcane and effects of population substructure. Theor Appl Genet 114(1):155-164

33. Welsh J, McClelland M (1990) Fingerprinting genomes using PCR with arbitrary primers. Nucleic Acids Res 18(24):7213-7218

\section{Supplementary Table}

Supplementary Table 3 is not available with this version.

\section{Figures}




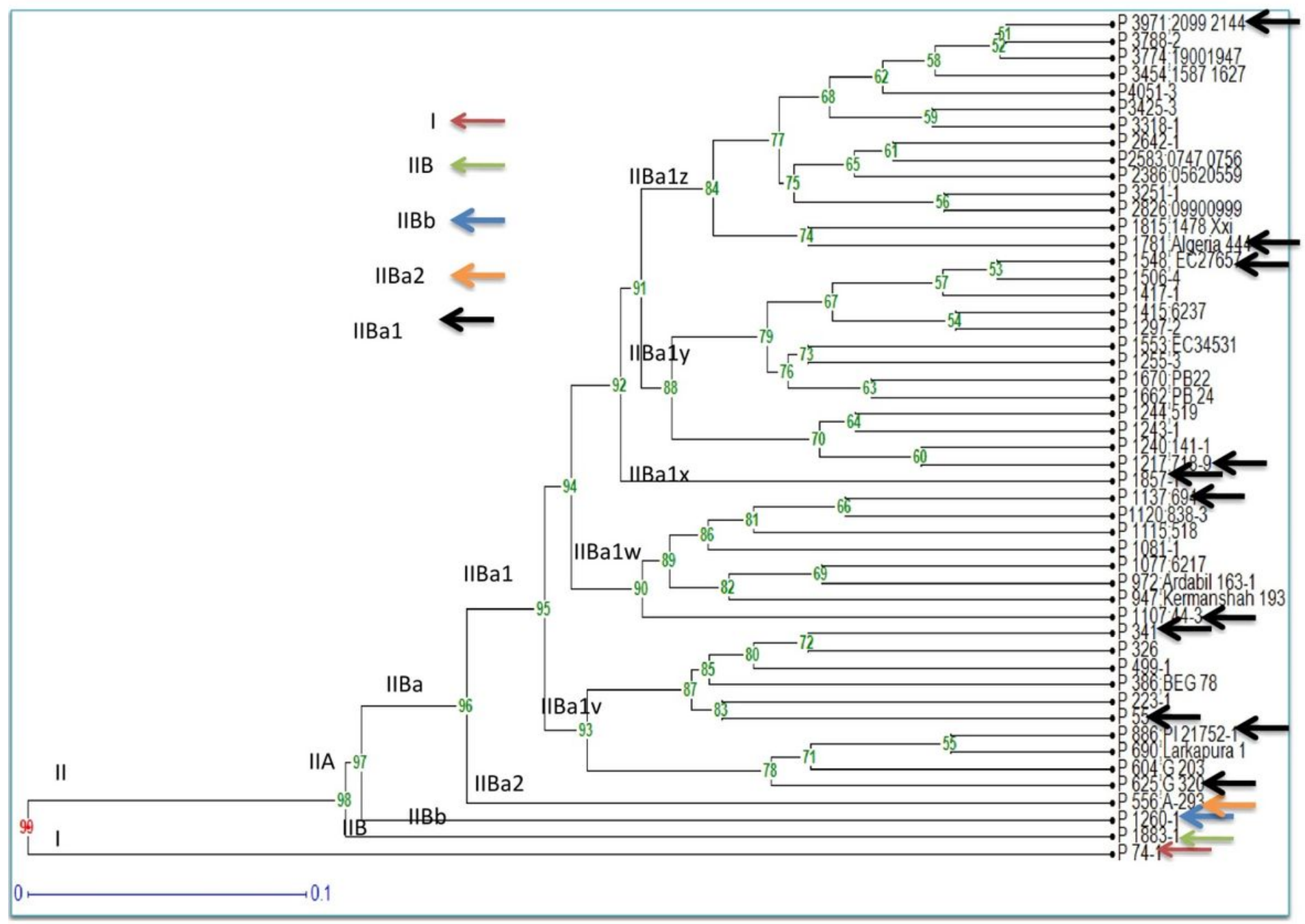

Figure 1

Dendrogram of 50 chickpea germplasms based on 23 inter simple sequence repeats (ISSR) markers 


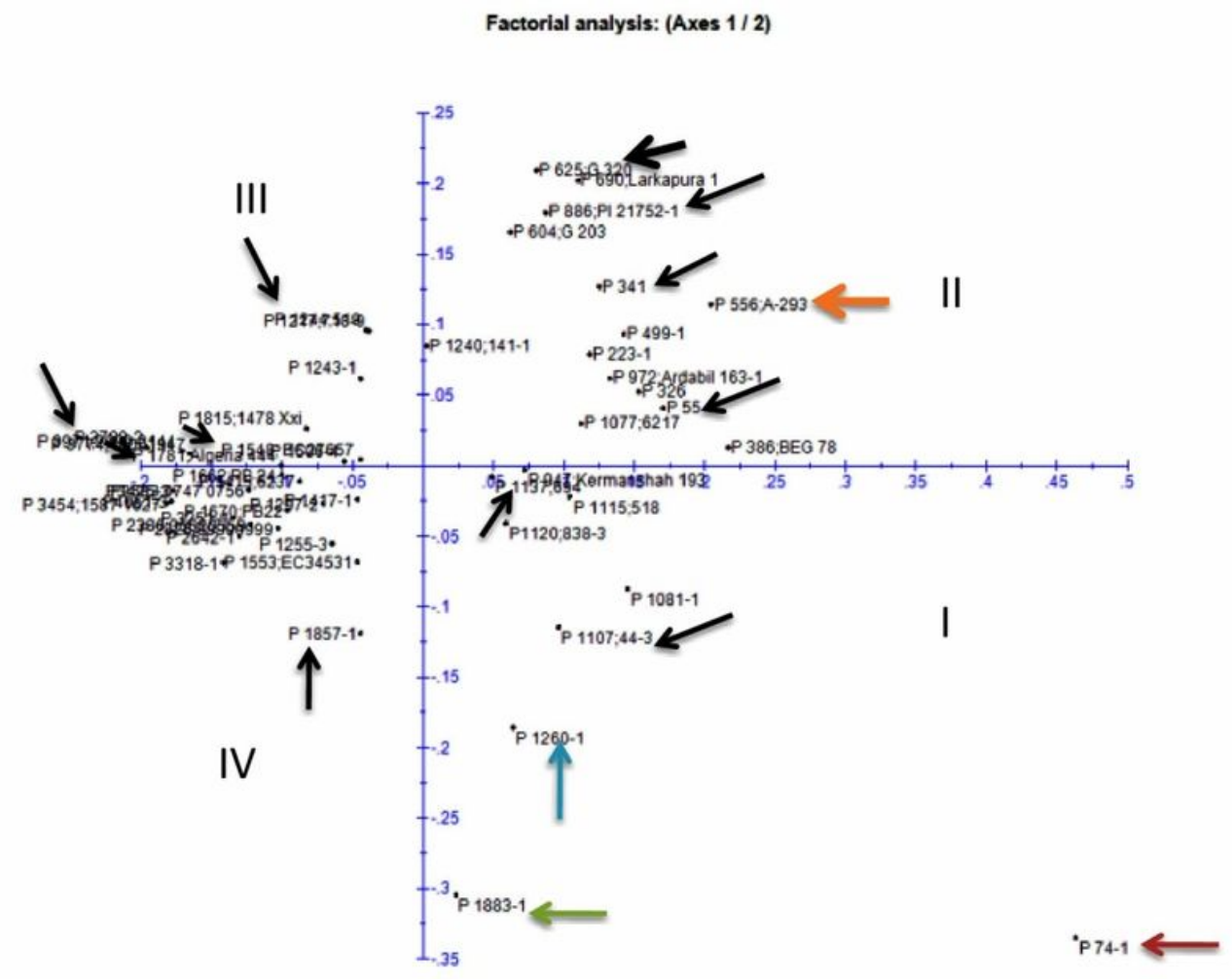

Figure 2

ISSRmarker based principle component analysis (PCA) showing two dimensional distributions of 50 chickpea germplasms 


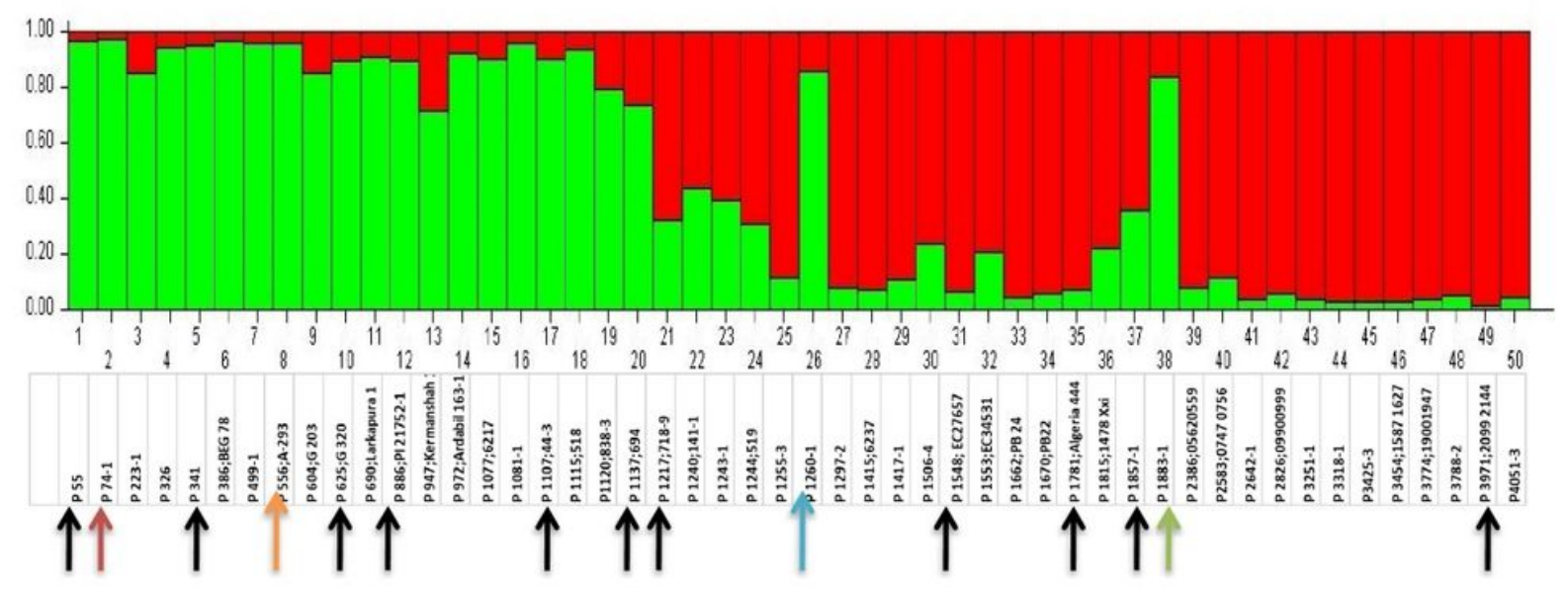

Dominating Green-cluster A

Dominating Red-cluster B

Figure 3

Bayesian model based genetic clustering of 50 chickpea germplasms 


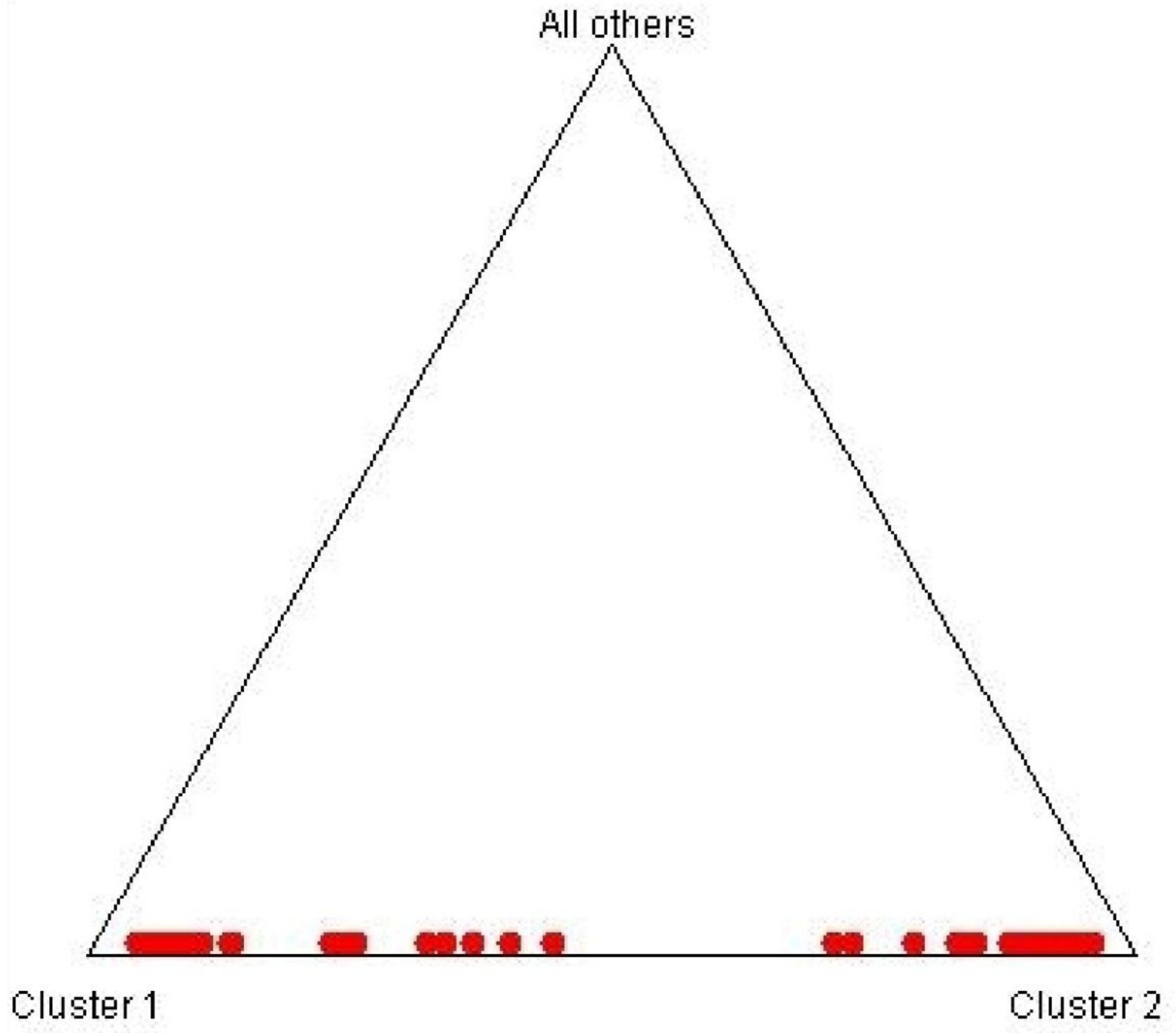

Figure 4

Trianle plot of 50 chickpea germplasms 
0.065 .0

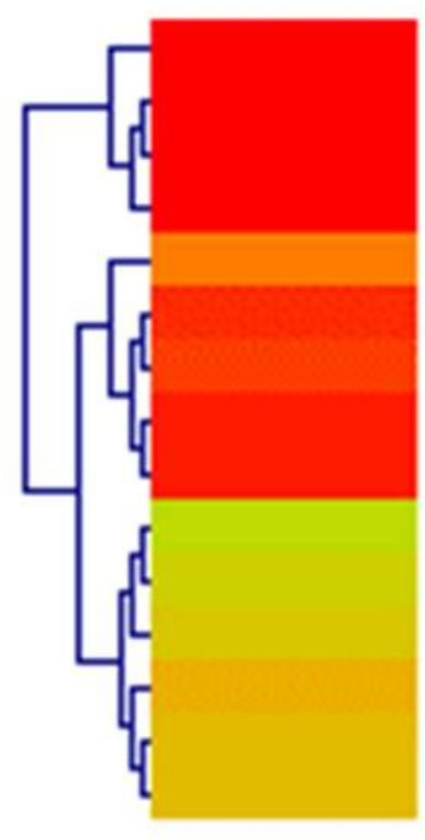

P $625 ; G 320$

P 55

P 1260-1

P 1883-1

P 1217; 718-9

P $556 ; \mathrm{A}-293$

Late

flowering

P $1107 ; 44-3$

P $1137 ; 694$

P 1548; EC 27657

P 74-1

P 341

P 1781; Al geria 444 Early

P 886 ; PI $217520-2$

flowering

P 1857-1

P 3971; 2099 2144

Figure 5

Heat map depicting early flowering profile of 15 chickpea germplasms

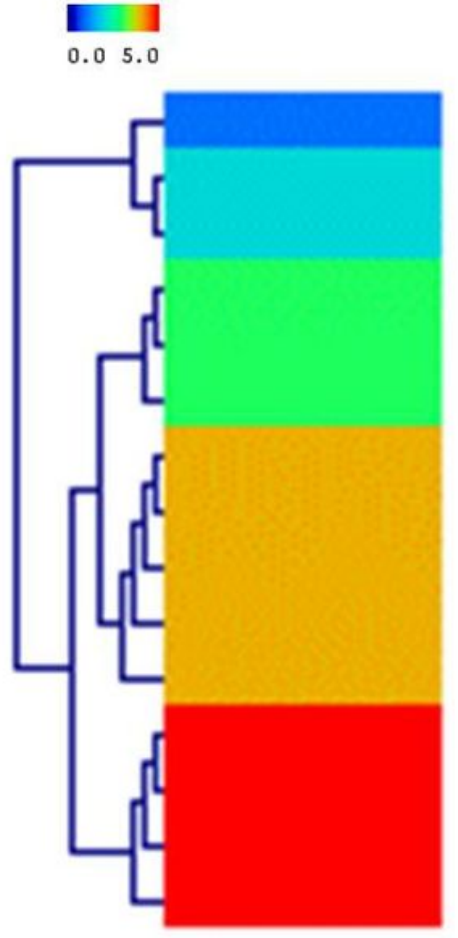

P $886 ;$ PI $217520-2$

P $1137 ; 694$

P 1883-1

P 55

P 74-1

P $625 ; G 320$

P 341

P $556 ; A-293$

P $1217 ; 718-9$

P 1548; EC 27657

P 1781; Algeria 444

P $1107 ; 44-3$

P $1260-1$

P 1857-1

P 3971; 2099 2144

High

Seed germination 
Figure 6

Heat map depicting high seed germination profile of 15 chickpea germplasm

\section{Supplementary Files}

This is a list of supplementary files associated with this preprint. Click to download.

- Supplementarytable1.docx

- Supplementarytable2.docx 